\title{
A simulation model for exploring the effects of plant-soil feedbacks on the resilience of plant communities
}

\author{
$\underline{\text { E.J. Trevenen }}^{\text {a }}$, L. Mucina a ${ }^{\text {a,c }}$, M.L. Trevenen ${ }^{a}$, A. K. Cresswell a,b and M. Renton ${ }^{\text {a }}$ \\ ${ }^{a}$ The University of Western Australia, Western Australia \\ ${ }^{b}$ Commonwealth Scientific and Industrial Research Organisation (CSIRO) \\ ${ }^{c}$ Stellenbosch University, Stellenbosch \\ Email: elizabeth.trevenen@,research.uwa.edu.au
}

\begin{abstract}
Plant-soil feedbacks (PSFs) are plant-induced changes to the abiotic and/or biotic properties of soil that positively or negatively impact plant growth. Recently, PSFs have been shown to play a key role in both promoting and maintaining high levels of diversity within plant communities. There is mounting evidence that diversity loss leads to reduced resilience of a community, which can be defined as an ecosystem's ability to recover following disturbance, and/or its ability to resist the disturbance's effects completely. PSFs may also positively influence the resilience of a community by promoting diversity, however this relationship is poorly understood. This is largely due to the complex and uncertain nature of such processes in natural systems, which renders empirical experiments unfeasible. Therefore, we aimed to develop a model capable of capturing the most important processes involved in the interactions among PSFs, diversity and resilience in diverse plant communities undergoing disturbance, in order to investigate how PSFs may affect plant community resilience at a theoretical level.
\end{abstract}

We used a cellular automata simulation model to simulate plant community dynamics over 1000 years. In order to observe community resilience within this time, communities were subjected to a range of disturbance regimes that consisted of multiple disturbance events which occurred at different frequencies and intensities within a 60 year period. Resilience was then quantified by comparing the trajectories of the communities based on their diversity (using inverse Simpson's Diversity Index) over time and following disturbance. In particular, the degree of change from the pre-disturbance state to the state immediately following disturbance was used to quantify resistance, and the rate of return to the pre-disturbance state following disturbance was used to quantify recovery.

The model was tested using four well-known and highly studied PSF scenarios that are observed in natural systems i.e. negative, positive and 2 types of no/neutral conspecific PSF. We found the PSF scenario involving negative conspecific PSFs to be the most resilient when subjected to the majority of the disturbance regimes, with a neutral scenario of no PSF and a slow growth rate being more resilient under high frequency disturbance regimes. Communities with positive conspecific feedbacks experienced the greatest loss of diversity following disturbance, which generally deteriorated with increasing frequency of disturbance. Positive conspecific communities also did not recover following disturbance and instead became less diverse as time went on.

These results are consistent with expectations based on the literature, suggesting the model is appropriate for exploring the effects of PSFs on the resilience of plant communities. Such research promises to greatly contribute to our understanding of how resilience is built within communities, which in part may assist restoration efforts aiming to return degraded ecosystems back to resilience.

Keywords: Cellular automata, community assembly, community resilience, disturbance, diversity 


\section{INTRODUCTION}

Plant-soil feedback (PSF) is a process whereby plants alter the biotic and abiotic properties of the soil they grow in, which in turn alters the growth performance of future plants in that soil (van der Putten et al., 2013). There is mounting evidence that PSFs significantly influence vegetation dynamics (Bennett et al., 2017; Bever, 2003; van der Putten et al., 2013), and recently PSFs have been shown to play an integral role in the promotion and maintenance of high levels of diversity (Teste et al., 2017). Since it is widely accepted that diversity loss leads to reduced resilience (May, 1973; Tilman et al., 1996; Tilman, 1999), it is essential to understand how changes in PSF interactions would influence community resilience.

Resilience can be defined as the resistance and recovery of a community following disturbance, with resistance referring to the degree to which a system is changed following a disturbance, and recovery being the time taken for an ecosystem to return to its pre-disturbance state after a disturbance (as first coined by Pimm, 1984). Considering the positive relationship between the presence of PSFs and diversity in combination with the positive relationship between diversity and resilience, it follows that PSFs may also positively influence the resilience of a community of plants. However, the relationship between PSFs and resilience is largely unexplored, partly due to the complexity and dynamism of natural systems making the collection of empirical data challenging, and in many cases, unfeasible.

To address such issues of complexity and dynamism, simulation modelling techniques are often employed. These techniques allow for control of conditions and variables that cannot be empirically controlled in natural systems. Stochastic cellular automata simulation models have proved useful for the purpose of investigating the effects of mechanisms, such as PSFs, on plant community dynamics (Mangan et al., 2010) and composition (Teste et al., 2017). Zee and Fukami (2015) explored how the presence of PSFs influenced the extent of diversity loss following habitat fragmentation through the use of a spatially explicit individual-based model. Their work revealed that the presence of PSFs greatly increased survivorship of communities undergoing fragmentation, which provided the first indications that PSFs may influence the resilience of communities. Although these studies provide important insights, more research is needed to understand how and when certain PSFs act as a mechanism that promotes resilience in a community and how this relationship changes over multiple disturbance events.

In order to investigate at a theoretical level how PSFs may affect plant community resilience, we aimed to develop a model capable of capturing the most important processes among PSFs, diversity and resilience. We then tested the model using four well-known and highly studied PSF scenarios that are observed in natural systems (i.e. negative, positive and 2 types of no/neutral conspecific PSF, see van der Putter et al., 2013). This model promises to greatly contribute to our understanding of the role that PSFs play in building the resilience of a system, which in part may assist restoration efforts aiming to return degraded ecosystems back to a resilient state.

\section{MODEL OVERVIEW}

We constructed a spatiallyexplicit stochastic cellular automata simulation model, based on a model previously developed by Teste et al., (2017) to integrate the empirically observed effects (ex situ) of soil feedbacks on the growth and abundance of 16 plant species over time. We adapted this model to now include disturbance events as well as seedbank dynamics.

Our adapted model simulates plant community dynamics with an annual time-step on a 100 by 100 square grid, with each grid cell being occupied by at most one individual plant. Each plant alters the 'soil' properties of its

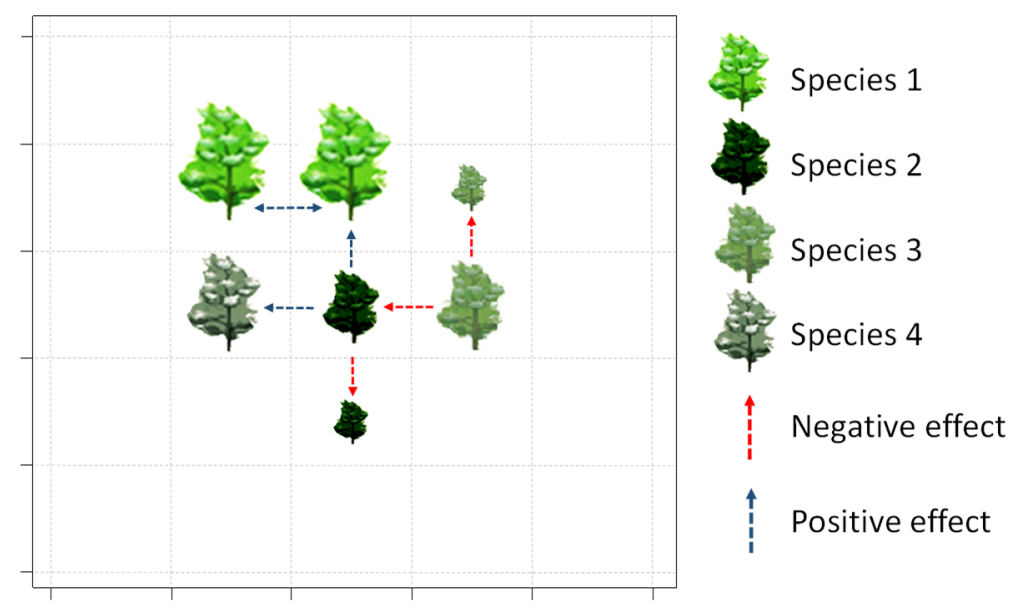

Figure 1. A schematic section of the spatially-explicit cellular automata simulation model used to investigate the effects of plant-soil feedbacks on community resilience. One plant occupies each cell and depending on the interaction between species, neighboring species can either enhance or hinder the growth of an individual plant. Individual plants may also affect the growth rate of the future occupants of that cell (not illustrated here). 
cell, which in turn can either have a positive, negative or no/neutral effect on the growth rate of the future occupant of that cell, or the growth rate of the plants in the neighbouring cells (Figure 1). Over time, the properties of the 'soil' of each cell will change, representing the fact that soil is gradually altered by resident plants.

A faster growth rate results in a larger plant with greater fecundity, thus larger plants have a greater recruitment probability (probability of populating empty cells). Large plants can influence their neighbour's growth, representing a simple competition scenario. The model is initialized by placing a plant of a set minimum size $\left(s_{\min }\right)$ in a proportion of the $100 \times 100$ cells. The remaining proportion of cells are intentionally left empty to reflect natural community densities. The species identity of each individual is chosen randomly from PSF matrices (see details of PSF scenarios (3)), which can represent 100 possible species $\left(n_{s p}\right)$, with each of the 100 species having an equal probability of occurring initially. Then, at each time step for the duration of the experiment (1000 years), the following processes occur in order: immigration, recruitment, growth and mortality.

Immigration: Immigration consists of giving each empty cell in the grid a chance to be populated by an immigrant from beyond the simulated area with a fixed probability $\left(p_{i m}\right)$. This represents the ability of a species from outside plant communities to repopulate the simulated world. The species identity of any new immigrants is chosen randomly from the 100 possible species.

Recruitment: When empty cells are not populated with an immigrant from beyond the simulated area, recruitment $\left(r_{e c}\right)$ from individuals within the simulated area can occur. The species identity of each of these new recruits is chosen randomly from the 100 possible species. However, larger plants have a probability weighting that is equal to the total size of all individual plants of that species in the simulated area at the time of recruitment. This represents the simple hypothesis that more abundant (i.e. more numerous and/or larger) plants are likely to produce more recruits. Recruitment can be set to either global or local, with local recruitment involving empty cell spaces being filled with seed from neighboring plant species, and global recruitment involving empty cell spaces being populated with seed from any plant existing in the simulated area. The option of global and local recruitment allows the implications of species dispersal range to be explored, i.e. under global recruitment all species have a greater dispersal range compared to local recruitment. Additionally, empty cells not occupied by an immigrant from beyond the simulated area may be repopulated by the previous occupant of the cell, representing seedbank dynamics. The seedbank dynamic consists of a seedbank decline rate $\left(s_{d r}\right)$, which represents the rate at which seed is lost from the soil annually.

Growth: The growth rates of individual plants depend on the intraspecific interactions in place from soil conditioning (see details of PSF scenarios (3)). The effect of these interactions on plant growth rates can either be delivered via the previous plants that occupied a cell or the neighboring plants $\left(E_{t}\right)$. Overall, all plants are constrained to a minimum size $\left(s_{\min }\right)$ and a maximum size $\left(s_{\max }\right)$.

Mortality - baseline: Plants larger than the minimum plant size $\left(s_{\min }\right)$ are subject to a baseline mortality rate $\left(M_{b}\right)$ representing general death and turnover in a community.

Mortality-disturbance regimes: Mortality also occurs in the case of a disturbance. Disturbance events involve the random removal of individuals from the model at several intensities $\left(M_{d}\right)$ and frequencies $\left(F_{d}\right)$. The intensity of the disturbance relates to how many individuals are randomly removed from the world at a specific point in time. Frequency refers to how often a disturbance is set to occur in a 60 -year time period.

\section{PLANT-SOIL FEEDBACK SCENARIOS}

We designed four PSF scenarios to represent the effects of different feedback interaction types on the resilience of the community (Table 1). Rates chosen to represent enhanced and hindered growth $\left(G_{r}\right)$
Table 1. A description of plant-soil feedback scenarios used for simulations.

\begin{tabular}{|c|c|c|}
\hline PSF scenario & $\begin{array}{l}\text { Conspecific } \\
\text { feedback }\end{array}$ & Description \\
\hline $\begin{array}{l}\text { Null low growth } \\
\text { (Null low) }\end{array}$ & $\begin{array}{l}\text { Neutral i.e. } \\
\text { none }\end{array}$ & $\begin{array}{l}\text { All species grow at the slower rate } \\
(1.5 \times) \text { annually. }\end{array}$ \\
\hline $\begin{array}{l}\text { Null high growth } \\
\text { (Null high) }\end{array}$ & $\begin{array}{l}\text { Neutral i.e. } \\
\text { none }\end{array}$ & $\begin{array}{l}\text { All species grow at the faster rate }(2 \times) \\
\text { annually. }\end{array}$ \\
\hline $\begin{array}{c}\text { Negative } \\
\text { conspecific (NC) }\end{array}$ & -Negative & $\begin{array}{l}\text { All species grow at the faster rate } \\
(2 \times) \text {, except when grown in or nearby } \\
\text { soil conditioned by own species where } \\
\text { they grow at the slower rate }(1.5 \times) \\
\text { annually. }\end{array}$ \\
\hline $\begin{array}{l}\text { Positive conspecific } \\
\text { (PC) }\end{array}$ & + Positive & $\begin{array}{l}\text { All species grow at the slower rate } \\
(1.5 \times) \text {, except when grown in or } \\
\text { nearby soil conditioned by own } \\
\text { species where they grow at the faster } \\
\text { rate }(2 \times) \text { annually. }\end{array}$ \\
\hline
\end{tabular}


were $2 \times$ and $1.5 \times$ respectively. These values dictate whether a plant becomes 2 times as large (enhanced growth) or 1.5 times as large (hindered growth) every year. The growth rates chosen were derived from growth rate data recorded from species grown in a glasshouse PSF experiment (Teste et al., 2017).

\section{TREATMENT AND REPLICATION}

The four PSF scenarios were simulated under several disturbance regimes in which multiple disturbance events occurred at different frequencies and intensities (as shown in Table 2). The disturbance regimes all commenced at year 250 (allowing for community stabilisation) and continued for 60 years, finishing at year 310 . To allow for community recovery to be measured, each simulation was run for 1000 years in total. We also tested the PSF scenarios under a range of different parameter combinations (e.g. changing recruitment and/or effect type), to observe whether the effect of PSF on resilience changed under different conditions. Each PSF community consisted on 100 species $\left(n_{s p}=100\right)$ to represent a diverse and complex vegetation system. Due to the stochasticity of the model, each treatment combination was replicated 100 times. The final simulation combinations chosen to investigate the effects of PSFs on the resilience of the communities are summarised in

Table 2. Simulation combinations chosen to investigate the effects of PSFs on the resilience of the communities.

\begin{tabular}{cccccc} 
Immigration $\left(\boldsymbol{p}_{\boldsymbol{i} \text { im }}\right)$ & $\begin{array}{c}\text { Recruitment } \\
\left(\boldsymbol{r}_{\boldsymbol{e}}\right)\end{array}$ & $\begin{array}{c}\text { Effect } \\
\text { type }\left(\boldsymbol{E}_{\boldsymbol{t}}\right)\end{array}$ & $\begin{array}{c}\text { Seedbank } \\
\text { decline } \\
\text { rate }\left(\boldsymbol{S}_{\boldsymbol{d} \boldsymbol{r}}\right)\end{array}$ & $\begin{array}{c}\text { Mortality- } \\
\text { disturbance } \\
\left(\boldsymbol{M}_{\boldsymbol{d}}\right)\end{array}$ & $\begin{array}{c}\text { Frequency of disturbance } \\
\left(\boldsymbol{F}_{\boldsymbol{d}} ; \text { measured in years }\right)\end{array}$ \\
\hline 0.02 & global & previous & 1 & 0.9 & $2,3,4,5,6,10,12,15,20,30,50$ \\
$0.01,0.02,0.03,0.05,0.07$ & global & previous & 1 & 0 & 0 \\
0.03 & global & previous & 1 & 0.9 & 6 \\
$0.01,0.02$ & global & previous & 1 & 0.9 & $4,6,8,12$ \\
0.02 & global & previous & 1 & $1,0.9,0.7,0.5$ & $2,6,10$ \\
0.02 & global & previous & $0.9,0.7$ & 0.9 & $2,6,10$ \\
0.02 & local & previous & 1 & 0.9 & $2,6,10$ \\
0.02 & local & neighbour & 1 & 0.9 & $2,6,10$ \\
0.02 & global & neighbour & 1 & 0.9 & $2,6,10$ \\
0.01 & global & previous & 0.9 & 0.9 & 6 \\
0.01 & local & previous & 1 & 0.9 & 6 \\
0.01 & global & previous & 1 & 0.9 & 6 \\
0.01 & local & previous & 0.9 & 0.9 & 6 \\
\hline
\end{tabular}

Table 2. All combinations were run under with the following set parameters $M_{b}=0.05, s_{\min }=0.01, s_{\max }=0.22$ and $\mathrm{n}_{\mathrm{sp}}=100$.

\section{DATA ANALYSIS}

Resilience was quantified by comparing the trajectories of the communities based on their diversity over time and following disturbance. In particular, the degree or change from the pre-disturbance state to the state immediately following disturbance was used to quantify resistance, and the rate of return to the pre-disturbance state following disturbance was used to quantify recovery. The inverse Simpson's Diversity Index (1/D) was used as the diversity index to calculate resistance and recovery as it takes into account both the number of species present, as well as the abundance/collective biomass of each species. Generalized least squares regression models were conducted to determine the statistical significance of observed differences between the four PSF scenarios at particular times: pre-disturbance (year 250), immediately following disturbance (year 311 ) and at the end of the simulation (year 1000), as well as for calculated resistance and recovery. Post-hoc pair-wise comparisons were performed using Tukey's HSD test. Significance was set at the 5\% level and data were analysed using the $\mathrm{R}$ environment for statistical computing (R Core Team, 2017).

\section{RESULTS}

Varying the PSF scenarios had a significant effect on both the resistance and recovery of the simulated communities, as measured by the inverse Simpson's diversity index (Table 3). The effect of PSFs

Table 3. Changes in the mean Inv. Simpson's diversity index corresponding to a disturbance frequency of every 6 years. Different letters correspond to significant differences $(\mathrm{p}<0.05)$ between values.

\begin{tabular}{lrrrrr}
$\begin{array}{l}\text { PSF } \\
\text { scenario }\end{array}$ & \multicolumn{1}{l}{$\begin{array}{l}\text { Pre- } \\
\text { disturbance }\end{array}$} & $\begin{array}{l}\text { End of } \\
\text { disturbance }\end{array}$ & $\mathbf{1 0 0 0 y r}$ & Recovery & Resistance \\
\hline Null low & $85.29^{\mathrm{a}, \mathrm{c}}$ & $8.12^{\mathrm{b}}$ & $14.78^{\mathrm{c}}$ & $0.01^{\mathrm{c}}$ & $77.17^{\mathrm{c}}$ \\
Null high & $85.56^{\mathrm{a}}$ & $9.98^{\mathrm{a}}$ & $18.90^{\mathrm{b}}$ & $0.01^{\mathrm{b}}$ & $75.58^{\mathrm{b}}$ \\
NC & $85.94^{\mathrm{a}}$ & $10.20^{\mathrm{a}}$ & $28.64^{\mathrm{a}}$ & $0.03^{\mathrm{a}}$ & $75.74^{\mathrm{a}}$ \\
PC & $84.85^{\mathrm{c}}$ & $1.41^{\mathrm{c}}$ & $1.09^{\mathrm{d}}$ & $-0.00^{\mathrm{d}}$ & $83.44^{\mathrm{d}}$ \\
\hline
\end{tabular}


on the resistance and recovery of the communities changed with increasing frequency of disturbance (Figure 2). At high disturbance frequencies (disturbance every 2-3 years), communities with no PSF and a slow growth rate (Null low growth) were the most resilient. Although the Null low growth community did not have the fastest recovery rate of the PSF scenarios, its impressive resistance (smallest loss of diversity following disturbance) to high frequency disturbance events resulted in it being the most resilient of the PSF scenarios at such frequencies. As the frequency of disturbance decreased (disturbance every 4-50 years), communities with a negative conspecific feedback scenario $(N C)$ were observed to be the most resilient with the greatest
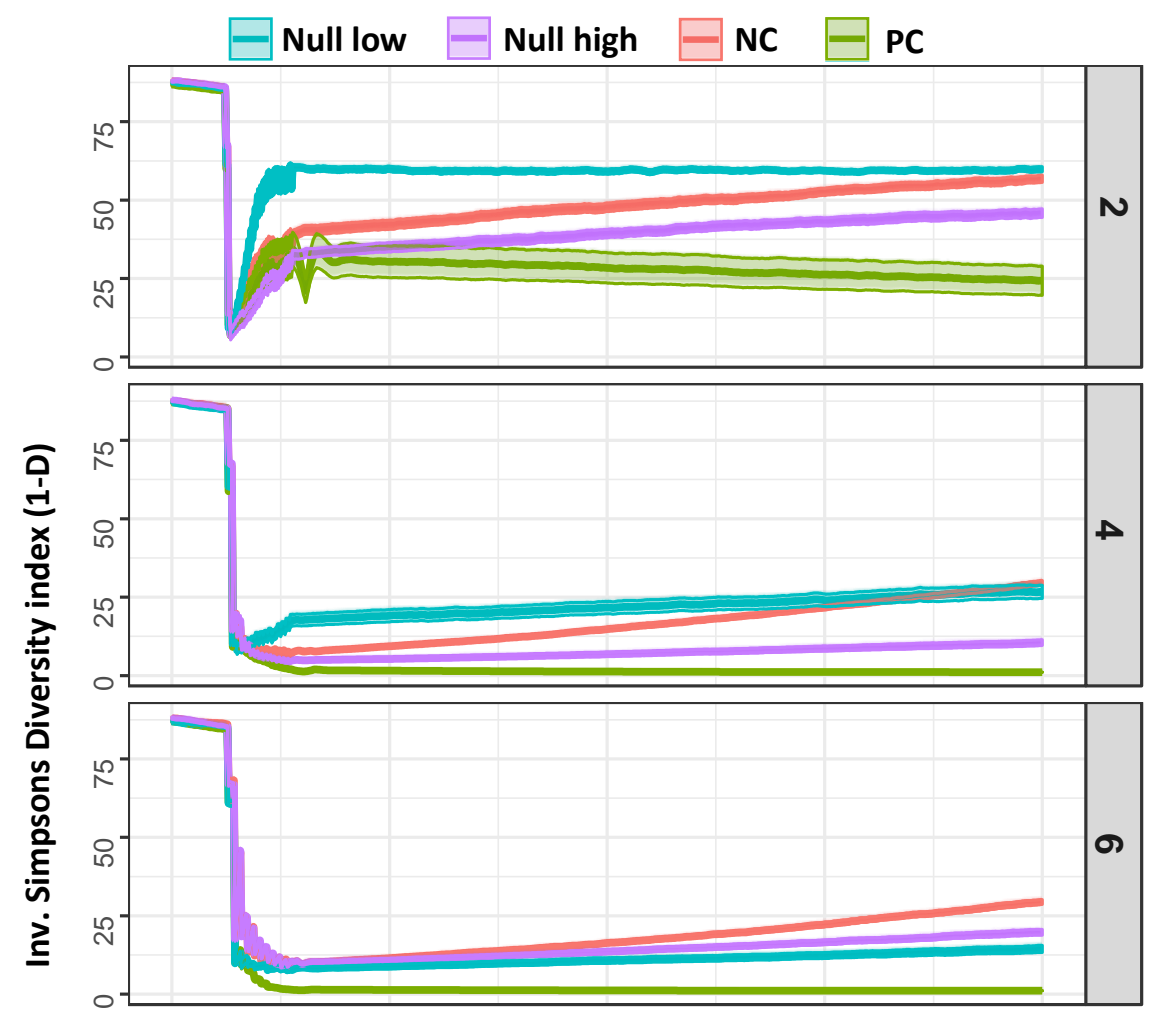
$\square$ Null low $\square$ Null high $\square$ NC $\square$ PC $\quad \begin{aligned} & \text { resistance } \\ & \text { disturbance, and the }\end{aligned}$ fastest recovery of diversity following disturbance.

Communities with positive conspecific feedbacks $(P C)$ experienced the greatest loss of diversity following these less frequent disturbance events, which generally worsened with increasing frequency of disturbance. $P C$ communities also did not recover following disturbance and instead became less diverse as time went on. Overall, the resistance and recovery of all the PSF communities were greatest at the highest frequency of disturbance $\left(F_{d}=2\right)$, and poorest around the mid-range frequencies $\left(F_{d}=4\right.$ 6).

Increasing values for immigration $\left(p_{\text {im }}\right)$, seedbank dynamics $\left(s_{d r}\right)$, disturbance mortality $\left(M_{d}\right)$ all resulted in diversity recovering faster except for when disturbance events

occurred at a high

Figure 2. Inv. Simpson's Diversity over time for the four PSF scenarios before, during and following a period of regular disturbance (years 250-310), with different disturbance frequencies (different rows). Null low growth is depicted in blue, Null growth high in purple, $N C$ in red and $P C$ in green. Thickened coloured lines represent the mean diversity at each time for each group. Shaded areas represent the $95 \%$ confidence intervals from each mean. frequency $\left(F_{d}=2\right)$. In this situation, patterns in diversity experienced little change. In all cases having local recruitment instead of global recruitment also resulted in diversity recovering more quickly. Simulations where the effect of PSF on plant growth rates were driven by the previous plant occupying the cell (i.e. $E_{t}=$ previous) saw a greater positive effect on resistance and recovery, as compared with simulations where $E_{t}=$ neighbour, where the response on the communities to disturbance was more uniform. Overall, the sensitivity analyses showed that the observed differences in diversity resulting from different growth rates under the four PSF scenarios were not dependent of the details of additional assumptions made in the model related to mortality, immigration, effect type, dispersal and seedbank dynamics. 


\section{DISCUSSION}

Our results indicated that PSFs have a significant effect on both the resistance and recovery of simulated plant communities as shown through changes in diversity. The scenario involving negative conspecific PSFs (NC) was the most resilient when subjected to most of the disturbance regimes, with a scenario of no PSF and a slow growth rate (Null growth null) being more resilient under high frequency disturbance regimes. Communities with positive conspecific feedbacks $(P C)$ experienced the greatest loss of diversity following disturbance, which generally deteriorated with increasing frequency of disturbance. Positive conspecific communities did not recover following disturbance and instead became less diverse as time went on. The way our positive conspecific and negative conspecific PSF communities effected the diversity of the community over time is consistent with current theory on the role of conspecific feedbacks in determining community assembly and diversity, as well as trends observed in real systems.

It is widely accepted that negative conspecific PSF promote co-existence and diversity (Bever, 2003; Kulmatiski \& Kardol, 2008; van der Putten et al., 2013), whereas positive conspecific PSF promote species dominance and consequent loss of diversity (Klironomos, 2002; van der Putten et al., 2013). Negative conspecific PSF encompasses any biotic or abiotic changes to the soil that negatively affect the growth of individuals of the same species. Conversely, positive conspecific PSF promote the growth of same-species individuals. Negative conspecific PSF may come about from a mechanism whereby species-specific soil pathogens begin to build-up as a given species increases in abundance. As the pathogens reduce the growth performance of the dominating species, their abundance in the community will in turn decrease (Laliberté et al. 2015). In contrast, positive conspecific PSF are suggested to be created from several processes one such being enemy release, where a species accumulates pathogens that its surrounding competitors are less resistant to (Kulmatiski \& Kardol, 2008). Regardless of the process, positive conspecific feedbacks are often related to plant dominance in a community which was consistent with the results of our simulations. In natural systems, such is often the case for alien invasive species which have frequently been recorded exhibiting positive or neutral conspecific feedbacks, giving them a competitive edge against comparable dominant native plant species which mostly exhibit negative conspecific feedbacks (Klironomos, 2002).

Our null scenario, with a slower growth rate (Null low growth) was seen to be more resilient than our null scenario with a fast growth (Null high growth) under all disturbances regimes that were simulated. Having a slower growth rate amounts to a reduced competitive ability. In a community comprised of only slow growing species, such as the Null low growth scenario, it is much harder for a particular species to break through and dominate. This consequently allows for greater coexistence and diversity within the community. Therefore, it is not surprising to see our Null low growth scenario, the only scenario where all species were slow growing, outperform other PSF scenarios under the same simulated disturbance regimes. This was particularly true during disturbance regimes with high frequencies, where the null low growth scenario was seen to exhibit greater resilience than the negative conspecific model. This may be because the high frequency of disturbance did not allow enough time for the negative conspecific feedbacks to effectively mitigate species dominance.

\subsection{Suitability of the model, Limitations and Future Directions}

To assess how well this model captured the processes involved in the interactions among PSFs, diversity and resilience for plant communities undergoing disturbance, we tested it using well-known and highly studied PSF scenarios: positive (PC), negative (NC) and neutral (Null low growth, Null high growth) conspecific feedbacks. We found the model to successfully return results that were consistent with the current theory, as well as trends observed in real systems, regarding the role of PSF in determining community diversity. The model was able to capture the complex interactions of many plant species over long periods of time, taking into consideration immigration, recruitment, seedbank dynamics, competition, growth and mortality. From this, we consider the model adequate for exploring the effect of PSF on community resilience and assembly.

Several limitations of our work point to future research directions. Firstly, the PSF scenarios only consider conspecific interactions. For future analyses, we aim to include heterospecific interaction scenarios to not only better reflect natural systems, but also to explore how different arrangements of heterospecific interactions influence community resilience. Secondly, our model assumes that PSFs are invariant through time and space. However, several studies have shown that in nature PSF can not only change over time through processes such as phenotypic plasticity and evolutionary responses (Thrall et al., 2007, Schweitzer et al., 2014 ), but also across abiotic conditions, such as altered levels of the soil nutrient availability (i.e. nitrogen and phosphorus) during long-term soil and ecosystem development (Png, 2017). How such changes may affect the resilience of communities remains unclear. Therefore, future work aimed at exploring such effects should incorporate elements that allow for the PSFs to change over time and space. The results will include a more heterogeneous simulation "world" with pockets of differing or changing abiotic conditions. 
Trevenen et al. 2017, Simulating the effects of plant-soil feedbacks on the resilience of plant communities

With the increasing degradation of natural systems, there is a great demand for natural systems to be restored to return the fundamental functions and services of which we depend on. It is now highly recognised that such restored systems will need to be resilient to guarantee that the valuable functions and services are not lost following disturbance events. To ensure the success of restoration efforts, we need to understand how resilience is built within a community. Models such as ours provide a great opportunity to start exploring the complex relationship between PSF, diversity and resilience.

\section{ACKNOWLEDGMENTS}

This research was funded by the Australian Research Council (ARC Grant LP150100339).

\section{REFERENCES}

Bennett, J. A., Maherali, H., Reinhart, K. O., Lekberg, Y., Hart, M. M., \& Klironomos, J. (2017). Plant-soil feedbacks and mycorrhizal type influence temperate forest population dynamics. Science, 355(6321), 181-184.

Bever, J. D. (2003). Soil community feedback and the coexistence of competitors : conceptual frameworks and empirical tests. New Phytologist, 157, 465-473.

Klironomos, J. N. (2002). Feedback with soil biota contributes to plant rarity and invasiveness in communities. Nature, 417, 67-70.

Kulmatiski, A., \& Kardol, P. (2008). Getting Plant - Soil Feedbacks out of the Greenhouse : Experimental and Conceptual Approaches. Progress in botany, 449-472.

Laliberté, E., Lambers, H., Burgess, T. I., \& Wright, S. J. (2015). Phosphorus limitation, soil-borne pathogens and the coexistence of plant species in hyperdiverse forests and shrublands. New Phytologist, 206, 507521.

Mangan, S. A., Schnitzer, S. A., Herre, E. A., Mack, K. M. L., Valencia, M. C., Sanchez, E. I., \& Bever, J. D. (2010). Negative plant-soil feedback predicts tree-species relative abundance in a tropical forest. Nature, $466,752-756$.

Pimm, S. L. (1984). The complexity and stability of ecosystems. Nature, 307(5949), 321-326.

Png, GK. (2017). Symbiotic nitrogen fixation during long-term ecosystem development: environmental constraints and ecological consequences, Ph.D. thesis, University of Western AustraliaR Core Team (2017). R: A language and environment for statistical computing. R Foundation for Statistical Computing, Vienna, Austria.

van der Putten, W. H., Van Der, Bardgett, R. D., Bever, J. D., Bezemer, T. M., Casper, B. B., Fukami, T., Kardol, P., et al. (2013). Plant - soil feedbacks : the past, the present and future challenges. Journal of Ecology, 101, 265-276.

Schweitzer, J. A., Juric, I., Voorde, T. F., Clay, K., Putten, W. H., \& Bailey, J. K. (2014). Are there evolutionary consequences of plant-soil feedbacks along soil gradients?. Functional Ecology, 28(1), 55-64.

Teste, F. P., Kardol, P., Turner, B. L., Wardle, D. A., Zemunik, G., Renton, M., \& Laliberté, E. (2017). Plantsoil feedback and the maintenance of diversity in Mediterranean-climate shrublands. Science, 355, 173176.

Thrall, P. H., Hochberg, M. E., Burdon, J. J., \& Bever, J. D. (2007). Coevolution of symbiotic mutualists and parasites in a community context. Trends in Ecology \& Evolution, 22(3), 120-126.

Tilman, D. (1999). The ecological consequences of changes in biodiversity: A search for general principles 101. Ecology, 80(5), 1455-1474.

Tilman, D., Wedin, D., \& Knops, J. (1996). Productivity and sustainability influenced by biodiversity in grassland ecosystems. Nature, 379(6567), 718-720.

Zee, P. C., \& Fukami, T. (2015). Complex organism-environment feedbacks buffer species diversity against habitat fragmentation. Ecography, 38(4), 370-379. 